\title{
Using Cloud, Modularity, and Make-to-Upgrade Strategy for Integrating Customized-Oriented Supply Networks
}

\author{
Afshin Mehrsai ${ }^{1, *}$, Hamid-Reza Karimi ${ }^{2}$, and Klaus-Dieter Thoben ${ }^{1}$ \\ ${ }^{1}$ BIBA - Bremer Institut für Produktion und Logistik GmbH \\ Hochschulring 20,28359 Bremen, Germany \\ mehabiba . uni-bremen. de \\ ${ }^{2}$ Department of Engineering, University of Agder, Grimstad, Norway
}

\begin{abstract}
In the current global business individual demand play crucial roles. Customized-oriented supply networks are being proliferated in manufacturing industries, yet integration of their members is still quite challenging. As a practical solution, in this paper a new collaborative approach out of modularity structure, cloud computing, and a novel production strategy, called Make-toUpgrade (MTU), is suggested. The complementary aspects of these techniques are highlighted and briefly explained here. MTU is as a strategy for future products with new characteristics, e.g., upgradability.
\end{abstract}

Keywords: Supply Network Integration, Cloud Computing, Modularity, Make-to-Upgrade Production Strategy.

\section{Introduction}

The phenomenon of globalization has been influencing all kind of businesses, in particular, manufacturing industries. Thereby, a wide range of opportunities as well as threats has been introduced to enterprises, which cause their businesses to survive or collapse. In such an environment, customized orders by individual customers are no more dispensable but advantageous to pioneer enterprises. Employment of new business strategies, models, and technologies can assist enterprises and their supply networks (SNs) to be successful in the dynamic environment, i.e., volatile market, expansion of scale and scope, mass-customized demands, scarce resources, growing complexity, shifting authority from final producers to their suppliers and customers, etc., [1] [2]. On top of these challenges, paying attention to alternative customer demands with individual requirements - mentioned or not - while being integrated with other production and product stakeholders have got a high priority from enterprises. This concern has been interpreted by industries as the mass-customization (MC) strategy as well as individualization of products and operations. Initially, Davis [3] in 1987 coined the term of MC to reflect the large scope of providing personalized products and services [4]. Nevertheless, in dealing with the challenge of customization, isolated enterprises was no longer successfully functioning in the market. But they

\footnotetext{
* Corresponding author.
} 
rather needed to collaboratively perform in harmony with the other players in the context of SNs [5]. Therefore, coordinating, administrating, and orchestrating the operations of such enterprises have become the biggest organizational challenges, to be dealt with by their respective SNs. On the contrary, while cooperating with other supply members, individual enterprises, as independent entities, like to keep their own interests and concerns. This fact originates several contradictions between the members who have to competently cooperate and collaborate with each other to achieve the overall goal of the network. In that regard, exploitation of modularity approach as a new business structure, cloud computing as the state-of-the-art technology, and development of a new compatible production/delivery strategy, called Make-toUpgrade (MTU), together are seen as a novel solution for such customized-oriented SNs. Here, fulfillment of individual demands is sought, whilst harmonizing the entire production operations through a wide-range of virtual integrations. Indeed, the inherent structure of cloud computing and modularity, as distributed entities, but in a holistic body, make them quite adjustable techniques for being implemented on MC-oriented SNs. Moreover, MTU assists new performing SNs to exploit modularity in (product, process, and resource) for postponing the configuration of their finalproducts and enriching the scope via upgradability specification of modules.

In exploring this claim, first a brief literature review on customization, modularity and supply network integration (SNI) is given. Then modularity and MTU are shortly discussed. Compatibility of cloud for SNI is highlighted too. To verify the recommended strategy a discrete-event simulation model is experimented at the final section. The conclusion and prospective works are explained at the end of the paper.

\section{Review of Customization, Modularity, and SN Integration}

A Literature review unfolds the key role of $\mathrm{MC}$ in enabling industries to become competitive on the current and prospective market. Generally, MC aims at satisfying customers by means of considering their personality and subjective needs. This objective has been interpreted by producers as shifting from traditional mass-production (MP) to individualized products, while keeping the cost, volume, and efficiency of MP. Salvador et al. [9] say MC "is a mechanism that is applicable to most businesses, provided that it is appropriately understood and deployed". Thus, MC is about aligning an organization with its customers' needs including reasonable costs.To fulfill these requirements, several enablers of MC can be listed as methodologies and techniques [4], e.g., lean and agility, order elicitation, design postponement, design product platforms, supply chain (SC) coordination, decoupling point, manufacturing technologies like flexible manufacturing systems, and information technologies like cloud computing. On this basis, among several enablers of MC modularity and postponement strategy are seen as two main approaches of companies to producing large product diversity [10]. As Mikkola [11] explains MC "is enabled through modular product architectures, from which a wide variety of products can be configured and assembled". Kumar [12] says "... given that product modularity is a key element of a mass customization strategy". Modularity in design of products enables companies to employ assemble-toorder (ATO) production strategy throughout their SCs. However, other strategies like deliver-on-demand (DOD), make-to-order (MTO), or design-to-order (DTO), can also 
be adopted by customized-oriented companies. The purpose of these strategies is to integrate customers with various configurations into the several phases of product development and into production stakeholders, by means of devising a decoupling point (DP). Reijers et al. [14] explain the modularity as "the design principle of having a complex system composed from smaller subsystems that can be managed independently yet function together as a whole". Initially, modularity looks for the favorable goal of plug and play, which for SNs can be realized through cloud advantages. In this regard, Schön [2] defines a module as "a unit with strong connections between its components which can be removed non-destructively from a system as a whole".Generally, modularity approach can be applied to different aspects of an industrial system, i.e., products, processes, and resources [15], see figure 1. Modularity in product design plays a crucial role in customizing final products (goods) and in easing production procedure, whereas modularity in process [14] can assist companies to deliver sustainable, adaptable, flexible, and customizable services either as final products or manufacturing/logistics operations. Moreover, as Pereira [5] mentions, a managed integration of SCs is required to achieve competitiveness, revenue, innovation, value, and cost reduction. However, he believes it is necessary to reevaluate the traditional and vertically integrated model of supply chains, by means of increased information sharing and cooperation, in order to achieve a global reach and local responsiveness. Bosona et al. [7] for SNI suggest close information sharing among several clusters and emphasize this importance in facing complex SNs. Winkler in [25] see the role of communication and information system throughout SNs as an important prerequisite for realizing flexibility as well as integration in SNs.Ye et al. [26] interpret SCI as integration of information. Some arguments about web-based information integrators are given that include the pros and cons of XML, extensible markup language (OWL), and extensible markup language (SWRL).

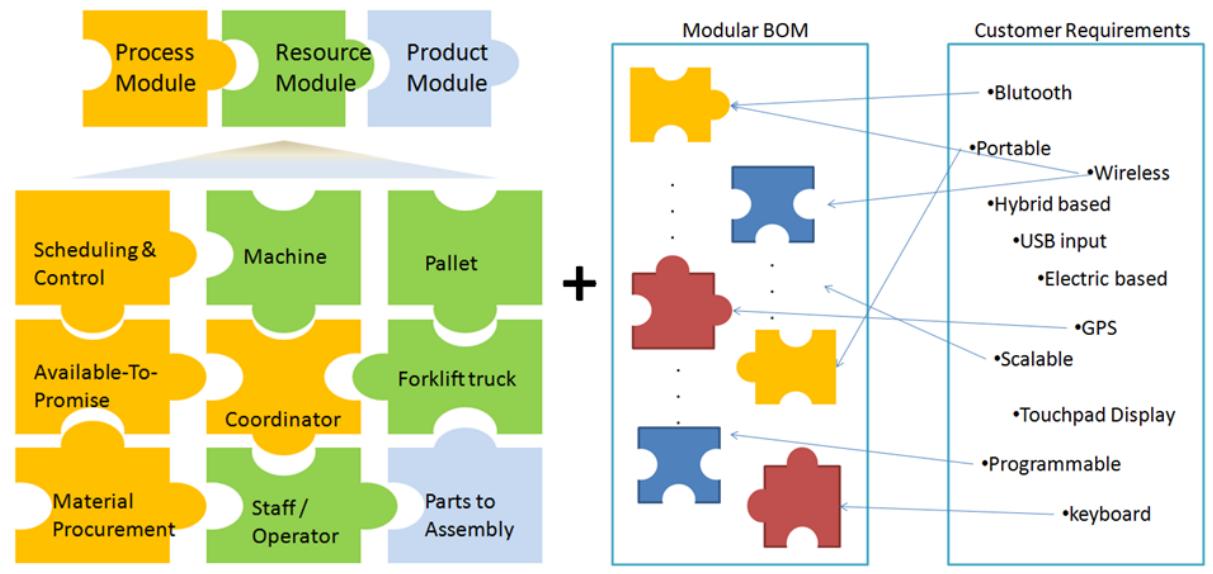

Fig. 1. Modular structure and customer integration in fulfilling MTU by using cloud privileges

All in all, regarding the characteristics of modularity and the mentioned requirements of SNI they seem quite compatible with each other. A common approach of the most studies on SNI refers to flexible, simple, and effective data integration. Thanks 
to new achievements in ICT and the proliferation of the cloud computing concept, these desires are getting closer to practice. Cloud with its novel distributed as well as integrated structure can complementarily contribute to this superior combination.

\section{Product Modularity and Make-To-Upgrade (MTU) Strategy}

In general, modularity in design of products brings about a large scale of product variety, while applying similar modules for alternative products (family). For instance, Porsche at a time period used a door module for three different car models. Or Nike, Adidas, and Dell follow the same concept of modularity to customize their products, yet by means of customer integration [20]. In the near future, thanks to modular body of products with new characteristics as upgradability and traceability (e.g., via product Avatar [17]), product obsolescence, waste, and scrap will drastically drop as great contributions to sustainability issue. By considering the specifications of such future products (called "meta-product" by FP7 EU), some advantages of modular vs. integrated design can be significantly highlighted as: scalability vs. non-scalability, simplicity vs. complexity, flexibility vs. rigidity, re-configurability vs. strictness, exchangeability vs. irreplaceability, upgradability vs. constancy or even downgradability, sustainability vs. non-sustainability (shorter lifecycle of modules by longer lifecycle of the entire product). These are some privileges of modular design, which directly contribute to the requirements of MC and MTU. A well-known example of such modular design is LEGO. Each of these accompanied characteristics with modular approach can be seen as a driver for developing a framework of future products in beyond the state of the art. Employment of Webpages for directly integrating customers to design their products is an outstanding advantage, which reflects demand penetration and ATO production strategies. Incorporation of customers towards the ramp-up phase of developing meta-products can be an extra privilege of customized-oriented SNs. However, early integration of customers, regarding various (individual) demands and some internal preparations [21], has its own difficulties and may not achieve an MC with efficient volume and cost [8]. Moreover, it can be easily distinguished that conventional products with customized features are more expensive and have longer lead times than the standard products [22]. In order to pursue the goal of "efficient and effective individualization" a new approach to production strategies seems necessary. Practitioners need to develop a special production strategy that supports the postponement of customization at the latest point (i.e., to facilitate smoother production and customization), while avoiding the conventional barriers of early customer integration. Indeed, the characteristics of future products (e.g., upgradability) provide an opportunity to manufacturers to develop standard modules, which can be easily assembled by end-users; to configure alternative final products without expensive modification in upstream echelons. This sought concept by modular product developers introduces a new production/delivery strategy, called by the authors (MTU), see figure 2. Pursuing the MTU strategy urges SNs to integrate the real customer requirements into their modular development phase as early as possible, whilst postponing the assembly of the modules and configuration of final products to the customer side. Member companies with the modularity approach set standard operations for producing their products (i.e., split in modules), while deriving modular processes at the very downstream of their SCs. Whereas MTU smoothes the production operations with a very adequate speed, customization is 
realized at its most competent level too. The MTU strategy may be more understandable once combining the performance of IKEA [16] and the concept of LEGO in postponement and modularity. Producers are virtually connected to consumers and get feedbacks to produce and upgrade their products in the form of compatible modules. However, the further step beyond the state of the art is to provide an environment to make possible the assembly phase of modules at the customer location. This draws a virtually integrated social network that all stakeholders of products are connected and engaged like the concept of product Avatar [17] existing on social networks like facebook [23] [24].

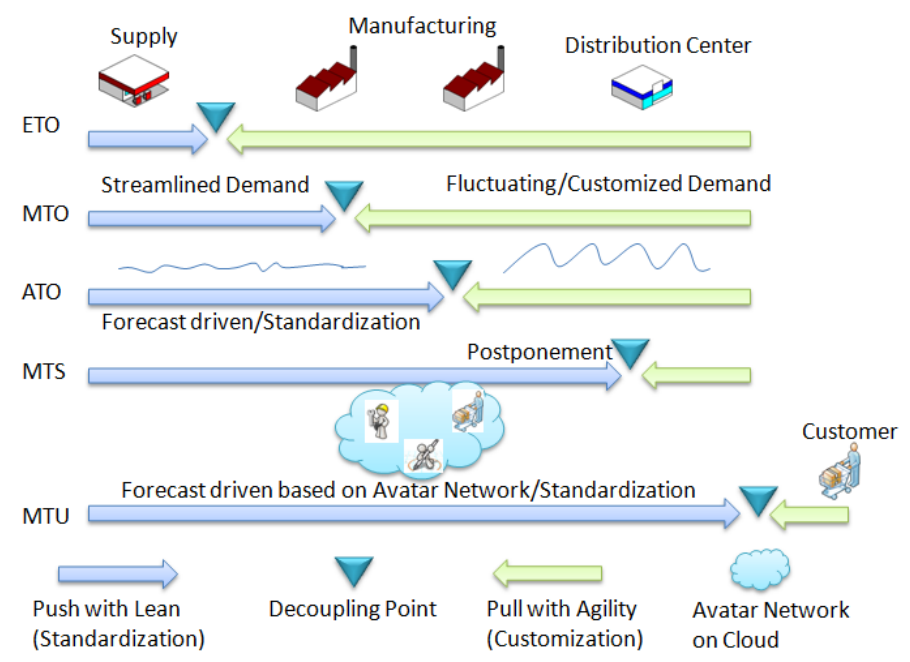

Fig. 2. Production strategies for developing MC product from state of the art to beyond

\section{Cloud and Integration}

In order to realize the modern approach to SNI and the recommended modularity's concept for the building-blocks of enterprises and the structure of SNs, cloud computing seems quite practical. Alternative forms of cloud services and the progressive development of each form, can positively comply with the integration of disturbed and heterogeneous entities. Once the cloud configures a virtual network, the entities of an industry from micro-scale (e.g., logistics objects) to macro-scale (network partners) can used the nature of cloud and even move beyond passive modules in a collaborative environment, i.e., towards autonomous units with collaborative capabilities on a common platform. Generally, cloud computing has several service and deployment models which can be employed for modular and autonomous systems. Some regular services are following [18], but not limited to: Infrastructure-as-a-Service (IaaS), Platform-as-a-Service (PaaS), Software-as-a-Service (SaaS). These main (XaaS) can positively cooperate to bring the concept of modular and autonomous entities in an SN closer to practice. Moreover, several deployment models of cloud can be imagined for logistics and production environments, employing recognized models as [19]: Private cloud, Community cloud, Public cloud, Hybrid cloud. However, their detailed contributions and compatibilities are not explained in this paper. 


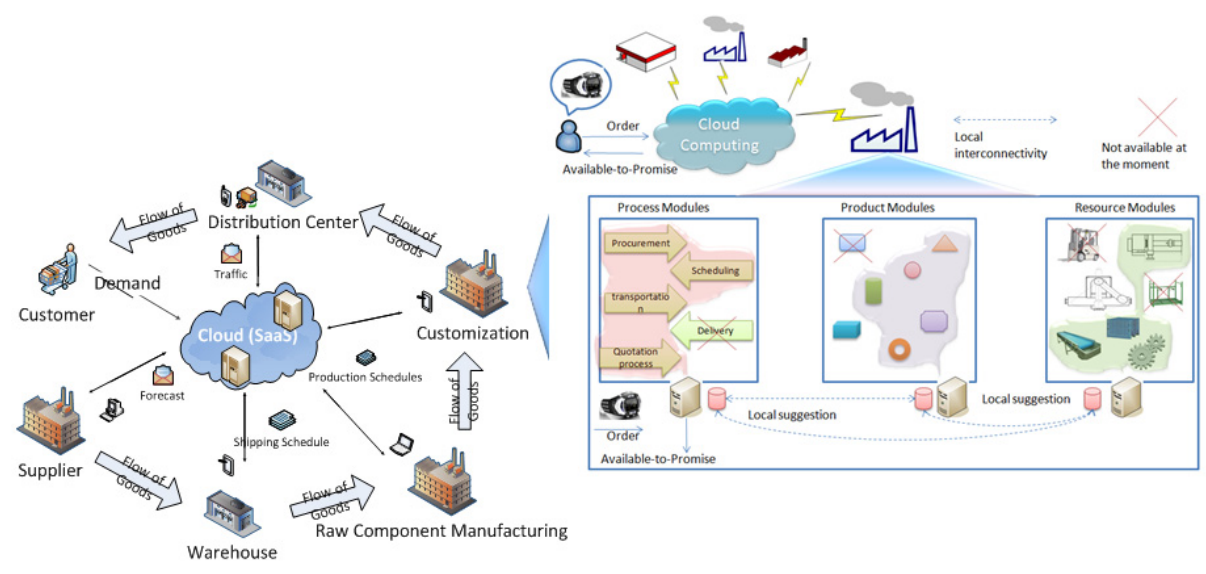

Fig. 3. Modular supply network by means of cloud computing

Indeed, development of a domestic as well as global cloud can provide a large common platform with alternative modules of processes, software, virtual product parts, virtual resources, and virtual suppliers; all with compatible interfaces for being joined together. In this regard, some advantages of cloud computing used by partners and SNs are [18]: improved business agility to get applications up and run quicker, reduced capital expenditure, increased end-user productivity and collaboration that improve manageability, and reduced energy consumption that leads to less maintenance. Accordingly, the idea of cloud computing for SNI (see figure 3) is inspired by several advantages. These issues can mainly be summaries as follows: 1) Narrow international competitions and the necessity of highly customized demands of international customers. 2) Deep interest for innovative products and production systems at superior flexible and agile enterprises/networks. 3) High complexity of organizing and coordinating endeavors in SNs with modular systems. 4) New developments in state-of-the-art ICT (e.g. autonomous entities, cloud computing) and their competent provided infrastructure. 5) Facilitation of employing best practices from domestic and global experiences through connectivity and learning, realizable by new structured cloud. 6) Profound desire for increasing productivity and efficiency in enterprises and SNs by new cooperative and collaborative networks to be facilitated by cloud and smart modules. 7) Great academic encouragement for recognizing real-time material flow control and prompt changeability of processes in practice.

\section{Exemplary SN Simulation}

In order to experiment the performance of prospective SNs by means of cloud computing for virtually integrating and optimizing the processes of network partners, a discrete-event simulation model is set up. The developed scenario out of a very simple SN reflects the applicability of cloud in organizing the flow of standard modules throughout the network from the source suppliers towards the customer side. Here, the mission of planning and control of flows is accomplished through cloud as SaaS, which is totally extendable to PaaS and IaaS in future works. The considered 
network is built out of four plants, i.e., a source plant, two parallel manufacturing plants, and an assembly plant (OEM), see figure 4 . There are three modules (A, B, C) of a final product, which each two module can configure a product to end up with three alternatives. The results of the simulation (table 1) are grouped in three experiments as planning via cloud: 1. for just OEM, 2. for just source plant, 3. for source and OEM simultaneously. The performance criteria for evaluating the network are average throughput time (Avg. TPT), standard deviation of TPT, and throughput per hour $(\mathrm{TP} / \mathrm{h})$. The results show that the best performance is for the experiment 3 .

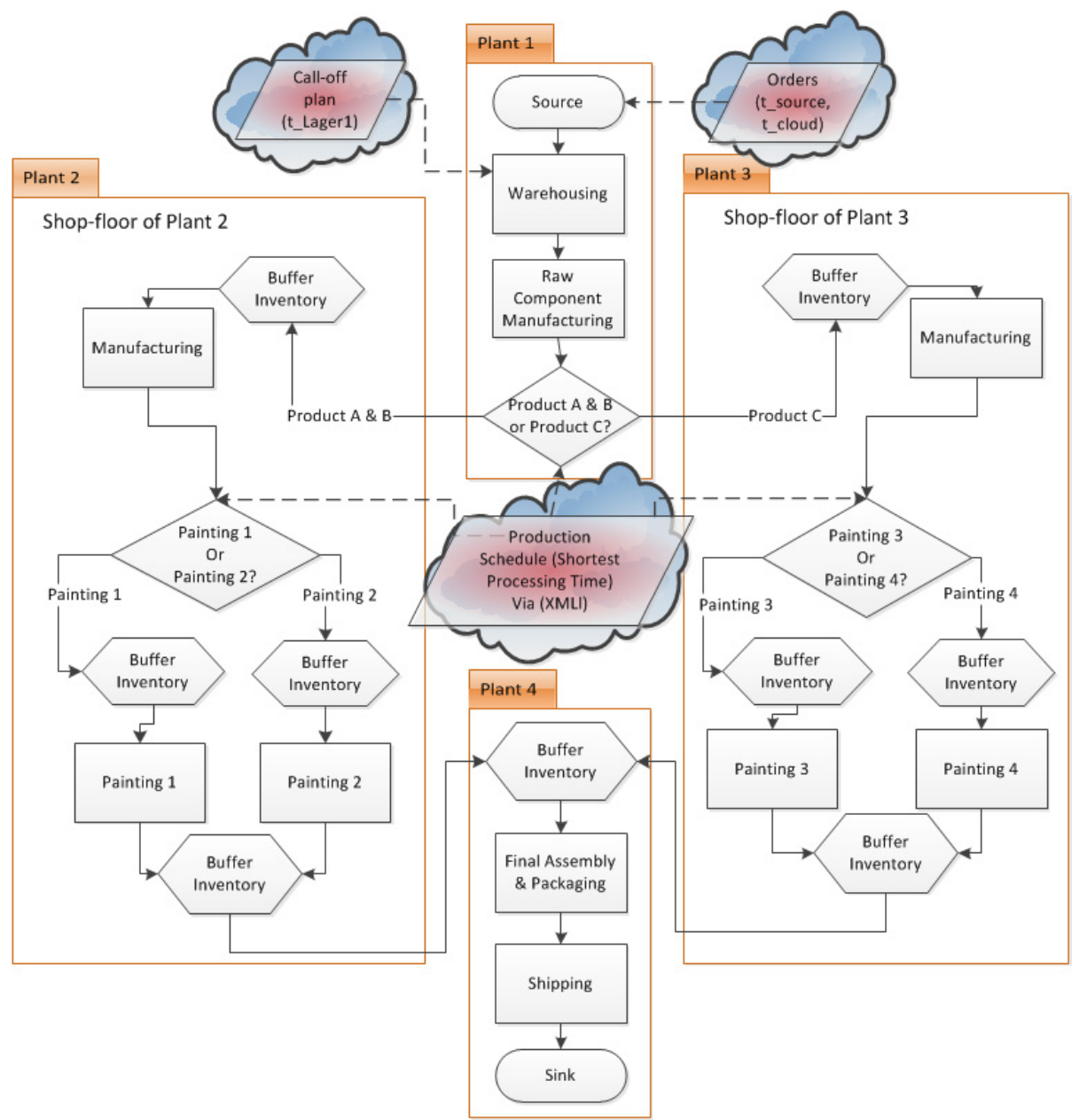

Fig. 4. Material and information flow of the network scenario

\section{Conclusion and Discussion}

In summary, the contribution of this paper to the ongoing challenges of current and prospective SNs included four major aspects as: integration of SNs, modularity 
structure (product, process, resource), MC and MTU production strategy, and cloud computing as web-based services. Among some potential alternatives (e.g., fully connected and coordinated SNs), this paper introduced a framework for complying with the production of individualized products. This suits to the turbulent global market using flexible and distributed, but integrated SNs. This novelty gives the opportunity to autonomous and distributed members of an SN to properly cooperate and collaborate with each other, whilst being coordinated at the cloud level. The advantage of the introduce framework encompasses: capability of promptly meeting market changes and quickly reconfiguring the structure of an enterprise or an SN (thanks to modularity, traceability, and upgradability), reducing investment in information systems, and competent coordination of all data exchange, using the common platform of cloud. Moreover, the simulation results proved the compatibility of modular design (for product, process, resource) with the common platform of cloud computing, employing distributed and virtual planning and coordination. The results showed that the more connected to the cloud the better performance of the network. As further works, exploration of different aspects of cloud computing in assisting the competitiveness of $\mathrm{SNs}$ is due. Alternative control approaches for coordinating heterogeneous modules of a network as well as the compatibility of alternative MTU has to be elaborated. Modularity in all aspects of industries is to be studied in later papers.

Table 1. Result of simulation in three experiment alternatives

\begin{tabular}{|l|l|l|l|l|}
\hline & Module type & Avg. TPT (h) & stddev. TPT (h) & TP/h \\
\hline \multirow{3}{*}{ Experiment 1 } & A & 244 & 78 & 3.75 \\
\cline { 2 - 5 } & B & 244 & 152 & 4.36 \\
\cline { 2 - 5 } & C & 249 & 146 & 2.96 \\
\hline \multirow{3}{*}{ Experiment 2 } & A & 245 & 157 & 1.12 \\
\cline { 2 - 5 } & B & 277 & 198 & 1.00 \\
\cline { 2 - 5 } & C & 118 & 67 & 1.00 \\
\cline { 2 - 5 } & A & 252 & 147 & 5.00 \\
\cline { 2 - 5 } & B & 109 & 42 & 3.31 \\
\cline { 2 - 5 }
\end{tabular}

\section{References}

[1] Abdelkafi, N.: Variety Induced Complexity in Mass Customization: Concepts and Management, vol. 7. Erich Schmidt Verlag \& GmbH (2008)

[2] Schön, O.: Business Model Modularity-A Way to Gain Strategic Flexibility? Controlling \& Management 56, 73-78 (2012)

[3] Davis, S.M.: From future perfect: mass customizing. Planning Review 17(2), 16-21 (1989)

[4] Fogliatto, F.S., da Silveira, G.J.C., Borenstein, D.: The mass customization decade: An updated review of the literature. International Journal of Production Economics 138(1), 14-25 (2012)

[5] Pereira, J.V.: The new supply chain's frontier: Information management. International Journal of Information Management 29(5), 372-379 (2009)

[6] Danese, P., Romano, P., Formentini, M.: The impact of supply chain integration on responsiveness: The moderating effect of using an international supplier network. Transportation Research Part E: Logistics and Transportation Review 49(1), 125-140 (2013) 
[7] Bosona, T.G., Gebresenbet, G.: Cluster building and logistics network integration of local food supply chain. Biosystems Engineering 108(4), 293-302 (2011)

[8] Smith, S., Gregory, C., Jiao, R., Chu, C.-H.: Mass customization in the product life cycle. Journal of Intelligent Manufacturing, 1-9 (2012)

[9] Salvador, F., De Holan, P.M., Piller, F.: Cracking the code of mass customization. MIT Sloan Management Review 50(3), 71-78 (2009)

[10] Da Cunha, C., Agard, B., Kusiak, A.: Design for cost: module-based mass customization. IEEE Transactions on Automation Science and Engineering 4(3), 350-359 (2007)

[11] Mikkola, J.H.: Management of product architecture modularity for mass customization: modeling and theoretical considerations. IEEE Transactions on Engineering Management 54(1), 57-69 (2007)

[12] Kumar, A.: Mass customization: metrics and modularity. International Journal of Flexible Manufacturing Systems 16(4), 287-311 (2004)

[13] Jacobs, M., et al.: Product and process modularity's effects on manufacturing agility and firm growth performance. Journal of Product Innovation Management 28(1), 123-137 (2011)

[14] Reijers, H.A., Mendling, J.: Modularity in process models: Review and effects. In: Dumas, M., Reichert, M., Shan, M.-C. (eds.) BPM 2008. LNCS, vol. 5240, pp. 20-35. Springer, Heidelberg (2008)

[15] Bask, A., et al.: The concept of modularity: diffusion from manufacturing to service production. Journal of Manufacturing Technology Management 21(3), 355-375 (2010)

[16] Bocconcelli, R., Tunisini, A.: Value Creation through Product Modularity: the User's Perspective. Use of Science and Technology in Business: Exploring the Impact of Using Activity for Systems, Organizations, and People 25, 165 (2009)

[17] Hribernik, K.A., Rabe, L., Thoben, K.-D., Schumacher, J.: The product avatar as a product-instance-centric information management concept. International Journal of Product Lifecycle Management 1(4), 367-379 (2006)

[18] Van der Molen, F.: Get Ready for Cloud Computing. Van Haren Pub. (2010)

[19] Chandrasekaran, M., Muralidhar, M., Dixit, U.: Online optimization of multipass machining based on cloud computing. The International Journal of Advanced Manufacturing Technology, 1-12 (2012)

[20] Wong, H., Lesmono, D.: On the evaluation of product customization strategies in a vertically differentiated market. International Journal of Production Economics (2013), http://dx.doi.org/10.1016/j.ijpe.2013.01.023

[21] Koufteros, X., Vonderembse, M., Jayaram, J.: Internal and External Integration for Product Development: The Contingency Effects of Uncertainty, Equivocality, and Platform Strategy. Decision Sciences 36(1) (2005)

[22] Xia, N., Rajagopalan, S.: Standard vs. custom products: Variety, lead time, and price competition. Marketing Science 28(5), 887-900 (2009)

[23] Wuest, T., Hribernik, K., Thoben, K.-D.: Can a Product Have a Facebook? A New Perspective on Product Avatars in Product Lifecycle Management. In: Rivest, L., Bouras, A., Louhichi, B. (eds.) PLM 2012. IFIP AICT, vol. 388, pp. 400-410. Springer, Heidelberg (2012)

[24] Wuest, T., Hribernik, K., Thoben, K.-D.: Digital Representations of Intelligent Products: Product Avatar 2.0. In: Smart Product Engineering, pp. 675-684. Springer (2012)

[25] Winkler, H.: How to improve supply chain flexibility using strategic supply chain networks. Logistics Research 1(1), 15-25 (2009)

[26] Ye, Y., Yang, D., Jiang, Z., Tong, L.: An ontology-based architecture for implementing semantic integration of supply chain management. International Journal of Computer Integrated Manufacturing 21(1), 1-18 (2008) 